Síntesis:

Este documento plantea descriptivaanalíticamente el proceso de investigación

participativa que se desarrolló con los

habitantes del Conjunto Residencial

Bochica I y de algunos barrios aledaños en la localidad diez (Engativá), ubicada al occidente de Bogotá D.C., durante un año

y medio. Proyecto en el cual logramos generar espacios concebidos para el diálogo y la interacción, generando reconocimiento

e identidad entre los mismos residentes, reconstruyendo el tejido social y proponiendo políticas de convivencia en el sector.

Synthesis:

This document outlines descriptiveanalytically the process of participative investigation that was developed during a year and half with the inhabitants of the Conjunto Residencial Bochica I and with those from some neighborhoods bordering Localidad ten (Engativá), west of Bogotá. With such a project we were able to generate spaces conceived for the dialogue and

the interaction, generating recognition and identity among the residents themselves, reconstructing the social tissue and proposing politics of coexistence in the area.

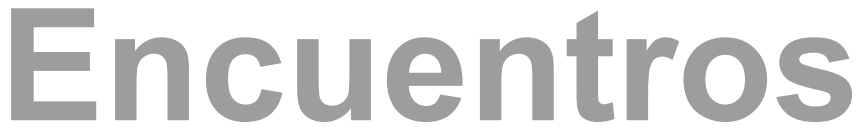

\section{comunitarios: Un aporte comunicativo para la convivencia en el Conjunto Residencial Bochica I ${ }^{1}$}

\section{Pilar Medina}

pilar_cita05@yahoo.com.ar

Patricia Quitián

patriciaquitian@hotmail.com

Comunicadoras Sociales - Periodistas. Facultad de Ciencias de la Comunicación. Uniminuto

iAl espíritu comunitario de aquellos líderes anónimos, que diariamente contribuyen con su vida a la realización de los sueños olvidados por

nuestra Nación!

Cuando iniciamos, nuestro objetivo fue legalizar el canal comunitario de Bochical, ya que este conjunto contaba con los recursos e infraestructura técnica para realizarlo. Como comunicadoras capacitaríamos a los habitantes para conformar un grupo de periodistas empíricos, que trabajarían al servicio de su gente.

\footnotetext{
${ }^{1}$ Trabajo de grado titulado "Encuentros comunitarios: Un aporte para la convivencia en el Conjunto Residencial Bochica I" sustentado en junio de 2004 para optar el título de: Comunicadoras Sociales - Periodistas de UNIMINUTO.
} 
La investigación y el trabajo constante con la comunidad nos hicieron ver que a los residentes de Bochica I no les interesaba tener un canal ni mucho menos trabajar en él.

Para ese tiempo (mayo de 2003), el Conjunto Residencial atravesaba por una dura ruptura administrativa que además desviaba la atención de los pocos participantes que logramos involucrar en el proceso.

A raíz de viejas riñas entre algunos delegados y miembros de anteriores administraciones, por privilegiar intereses particulares sobre los colectivos, se inició una dura división administrativa que acarreó fuertes conflictos en el barrio. Esta situación se presentó durante el desarrollo de este proceso.

Iniciamos el 24 de mayo de 2003, logrando abrir espacios para el diálogo e interacción dentro de la comunidad, dando paso al reconocimiento social, generando identidad y pertenencia en los residentes del Conjunto para construir, a través de estos espacios, políticas de convivencia en el sector.

\section{Introducción}

"No es posible la existencia de procesos exitosos de desarrollo local sin un componente identitario fuerte, que estimule y vertebre, el potencial de iniciativas de un grupo humano"2

Les cuento el milagro y no el santo "Trabajar con los pobres también da plata"3 y aunque el valor de un proceso

${ }^{2}$ AROCENA, José, El desarrollo local, un desafío contemporáneo. Centro Latinoamericano de Economía Humana (CLAEH), Universidad Católica del Uruguay, 1995.

${ }^{3}$ Refrán popular. de investigación no lo da el reconocimiento económico a menos que la ONU lo patrocine, la satisfacción del deber cumplido, las miles de sonrisas, los abrazos de gratitud y miradas de admiración, se convierten en la mayor recompensa; como dice mastercad: "hay ciertas cosas que el dinero no compra".

El conocimiento individual teje sus raíces sobre las realidades más cercanas, la sociedad, que con sus altibajos, es el digno reflejo de lo que se nació siendo o creyendo ser; lo cierto es que creyendo ser o siendo, cada persona es legítima por naturaleza y su reconocimiento como ser individual, transmite una riqueza invaluable a nuestro proceso de investigación; hay que atreverse, no existen ideas descabelladas, por eso sean arriesgados, sí ustedes, que están tan a tono con los desafíos y de paso lean nuestro trabajo de grado que se encuentra en la biblioteca de Uniminuto.

El aporte comunicativo logrado aquí, no hubiese sido posible sin la participación activa de la comunidad. Las acciones comunicativas entre unos y otros, son un instrumento de fortalecimiento que posee el hombre para la construcción de una cultura pensada desde lo local, desde lo nuestro. Sólo así, trabajando en equipo, desarrollamos una identidad social, donde se aporte a la democracia y a la convivencia en nuestro entorno como vecinos, como ciudadanos y como colombianos.

Las acciones comunicativas son un elemento transformador de la realidad, porque la comunidad no es solamente un espacio geográfico compartido, sino que allí dentro reside todo un mundo de significaciones y sentidos de vida, que atrapan, transforman y descubren el verdadero vivir, que se simplifica en que no existen fórmulas concretas para la consecución del progreso, esto es cuestión de sentido común. Por ello, este trabajo 
es hoy un escenario hacia la reflexión.

Nosotras aceptamos el reto de construir sociedad a partir de una iniciativa de salón, y hoy como profesionales, compartimos esta experiencia (que tantas satisfacciones aún nos entrega) con usted amable lector, para que la lea, la multiplique, la vuelva a leer y la convierta, al igual que nosotras, en un estilo de vida.

\section{La Investigación}

"Sólo es posible trasformar la realidad viéndola de otra manera" Frank Kafka

Cuando llegamos por primera vez a la comunidad, acudimos al comité de comunicaciones para conocer qué se hacía desde la Administración de Copropietarios de Bochica l, (como su nombre lo dice son quienes administran los recursos del sector y velan por su seguridad, protección y mantenimiento).

Montar el canal comunitario, producir notas periodísticas de carácter pedagógico, formar periodistas empíricos en el sector, aprovechando el recurso de la antena parabólica para consolidar el canal comunitario T.V. Bochica, eran nuestros objetivos iniciales después de conocer lo que se realizaba desde el comité de comunicaciones.

Nuestras propuestas apuntaban a incentivar a la comunidad a través de una convocatoria abierta para que participaran en un proceso de capacitación y de esta manera, se empoderarían de sus recursos e infraestructura. Un equipo humano con talento al servicio de los residentes, amigos y vecinos.

\section{Ciudadanías}

El trabajo que emprenderíamos consistió en aprender el manejo de equipos que posee el comité de comunicaciones (cámara VHS, luces, micrófonos y cableado), además de recibir talleres de formación sobre "cultura audiovisual" para que nuestros periodistas empíricos informaran a la comunidad sobre salud, cultura, educación y hasta entretenimiento; todo esto con el fin de darle continuidad al proceso que el comité venía adelantando cuatro años atrás.

Trabajar en conjunto por sacar adelante el noticiero T.V. Bochica, se convirtió en el desafío 20-03 para el equipo de cinco investigadoras que jugaban de locales: Catalina Bernal, Diana Casas, Pilar Medina, Patricia Quitián y Paola Sánchez.

El conjunto Residencial Bochica I cuenta con cuatro agrupaciones constituidas por 31 bloques, 24 locales en el centro comercial y 226 parqueaderos distribuidos: 96 en la zona A y B y 132 en las zonas C y D.

Al tener identificadas las zonas y los actores, se realizó una amplia convocatoria para hacer una presentación del equipo de trabajo con el fin de dar a conocer nuestros objetivos y hacerlos partícipes "(...) Cuando nosotros estamos con las comunidades, cuando los sabemos escuchar, estamos construyendo sociedad, sociabilidad, estamos construyendo democracia y ciudadanía porque estamos apelando a un otro que tiene palabra y al cual nosotros escuchamos" 4

No es nada fácil reunir a la gente, al comienzo todo nos salía al revés, cuando convocamos adultos venían niños, cuando convocamos niños venían adultos, sin

${ }^{4}$ ALFARO, Rosa María. Comunicación y ciudadanía para una sociedad en movimiento. Extracto de su ponencia en el seminario del año 2000. Asociación de Comunicadores Sociales CALANDRIA y Universidad de Lima, Perú. 

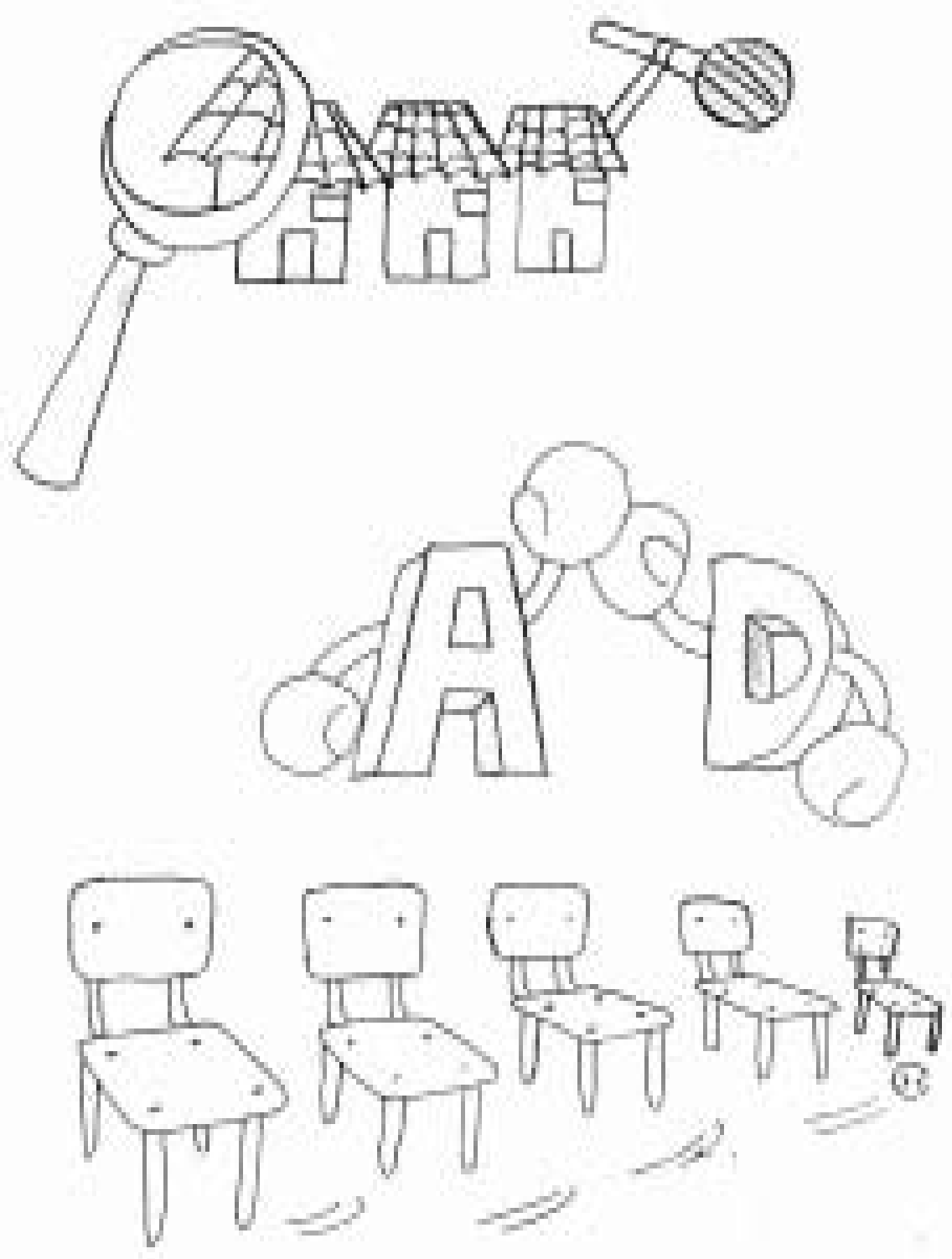

embargo, logramos identificar las necesidades y problemas pero no un grupo estable que le diera continuidad al proceso.

Los objetivos del proyecto que nos planteamos en un inicio, se fueron adaptando a las necesidades de la comunidad.

"A mí realmente llegar al movimiento comunal no me costó mucho trabajo. Eso lo lleva uno en la sangre. Usted sabe que la Acción Comunal es un trabajo sin ánimo de lucro, nosotros no devengamos ningún tipo de sueldo del Gobierno. Eso es como tener un carisma para poder servir y hacer los trabajos comunitarios" ${ }^{\prime \prime}$

De montar un canal comunitario en el sector, se pasó a realizar encuentros comunitarios como herramienta comunicativa en función de la conciencia de lo público, reto que solamente era posible identificando a los líderes del sector para que incentivaran a otros habitantes a participar.

${ }^{5}$ Departamento Administrativo de Acción Comunal del Distrito, Voces del común, testimonios de líderes comunales en Bogotá, capítulo 1, 1998, pág. 31. 


\section{Ciudadanías}

\section{Esto se puso bueno... y vean porqué}

El 24 de mayo de 2003 se inició el proceso de convocatoria en el sector. Por medio del canal comunitario del conjunto, se emitieron invitaciones a través de un crawlll ${ }^{6}$, distribución de volantes, afiches ubicados en cada una de las porterías de los bloques y divulgación con megáfono.

En la reunión daríamos a conocer nuestras intenciones como equipo de apoyo y se escucharían propuestas por parte de sus residentes. La asistencia estimada como mínima eran 20 personas, que brillaron por su ausencia.

Por esto replanteamos las estrategias de convocatoria pues debían atraer no espantar, además, era necesario buscar otros espacios donde distractores como el campeonato de fútbol a tan sólo $200 \mathrm{~m}$. del lugar no pudieran opacar nuestros objetivos.

El 14 de junio de 2003 se realizó una exitosa lunada. La participación de la comunidad fue masiva y nos permitió ser identificadas, no sabemos si fue la fogata, los cuenteros, los premios (que iban desde los \$1000 de pan patrocinado por "El pan de aquellas" hasta el corte de cabello "Donde Doña Conchita") o el carajillo quien atrajo a más de 100 personas entre niños, jóvenes, adultos y adultos mayores. Esto nos elevó los ánimos, pero nos dio una no muy grata sorpresa, todo iba tan bien... ya veíamos la luz.

Los residentes no estaban interesados en el canal, algunos no lo conocían o no lo habían visto, como dice

${ }^{6}$ Mensaje de texto circulante que se emite de manera horizontal en la parte inferior de la pantalla del televisior.
Shakira: "ciegos, sordos y mudos" sobre el tema. $Y$ como si fuese poco no querían impulsarlo. "Eso como pa'que": agregó un residente.

Quisimos realizar una base de datos para citar a las personas nuevamente y discutir esta situación pero nadie dio los teléfonos ni las direcciones electrónicas. El curso de capacitación en manejo de cámara y narración audiovisual no pudo efectuarse. Teníamos el corazón como una uva pasa y lo peor sin entender qué ocurría.

Cinco meses después y luego de varios talleres para impulsar el espíritu comunitario de los residentes y sus líderes administrativos, logramos establecer un plan de acción con "El resplandor de mis años", un grupo de adultos mayores. Paralelamente, se daba inicio a un proceso de división administrativa en el sector, que le dio un giro inesperado a nuestra investigación.

\section{El problema de la investigación}

Hasta el 1 de diciembre de 2003, en el Conjunto Residencial Bochica 1, los recursos de las cuatro zonas que lo integran ( $A, B, C$ y D) eran administrados por la Asociación de Copropietarios de Bochica I tal como se venía haciendo hace 22 años.

Las voces oficiales fueron: Fernando Dávila y Roberto Páez, presidente y secretario de la Junta de Acción Comunal, quienes nos contaron que: "Los motivos que impulsaron a tomar la decisión de la separación a la nueva administración fue por diferencias que desde años atrás, han marcado las relaciones entre las personas líderes del "otro bando" quienes son: Segundo Herreño Pico, Manuel Higuera, Zoraida Hernández, José Ignacio Sotelo y Danilo Sarmiento". 
"Ellos han querido montar su propia administración, afectándonos a nosotros «los de arriba», como nos dicen los de esa administración" afirma Dávila.

La nueva agrupación de las zonas A y B manifestó estar inconforme por los malos manejos de los recursos, por la interminable cartera morosa debido al incumplimiento del pago administrativo y de parqueaderos, por el descuido de las zonas comunes e infraestructura y dinero, que al parecer no está llegando a su destino, hecho que hasta el momento no se ha podido comprobar.

Las diferentes versiones entre los residentes y líderes (hablamos de más de 2000 habitantes) sobre el enfrentamiento en el mismo conjunto, creo un clima de desconfianza y confusión, no se sabia que era lo que realmente pasaba y las consecuencias de esto generó incertidumbre y caos colectivo.

La comunicación más que una ciencia es un estilo de vida, tan sencilla como profunda, divertida pero peligrosa y más cuando entramos a ser facilitadoras de un proceso de transformación social, que fortalece y potencializa el capital humano y la convivencia; si lo hablamos en términos televisivos, es un desafío 20-05, un reality sin cámaras pero con miles de ojos observándote con sigilo, que esperan con cautela eliminarte por convivencia.

Como dice Sidessteper: "Mira que la gente, ya no se calla, no vale la pena, dar más papaya", una gran oportunidad para continuar con nuestro trabajo como comunicadoras e investigadoras en esta comunidad y demostrarle a los residentes que problemas como estos debían ser orientados por profesionales, y bueno, ahí estábamos nosotras adquiriendo un gran compromiso social, una prueba que sin lugar a dudas nos merece la inmunidad.

\section{¡Qué bonita vecindad!}

La comunicación es un arma poderosa, por medio de ella trasmitimos informaciones, sentimientos y pensamientos. "La comunicación es un proceso de interaprendizaje, en el cual el papel de los medios es meramente instrumental". ${ }^{7}$

El Conjunto Residencial Bochica I empezaba a vivir el proceso de división administrativa y la desinformación era total, se hablaba de que la ley de propiedad horizontal había beneficiado a los de abajo "Zonas A y B", que perderían los residentes las zonas comunes, es decir, parques y zonas verdes, que quitarían el encerramiento y que despedirían personal de mantenimiento, pero nadie entendía nada, ni nosotras.

La Ley de Propiedad Horizontal 675 del 3 de Agosto de 2001 entró en vigencia el 3 de febrero de 2003, cobijando a la conformación de la nueva Agrupación de Copropietarios de las Zonas A y B. Esta ley apoya a la agrupación de personas que buscan el bienestar, la convivencia, el cuidado de la infraestructura y las normas de buena vecindad. iAhora sí quedamos como el principio!

Y entonces, ¿por qué el conflicto de la división, si dicha ley ampara a los propietarios del sector? Según Dávila, la manera en que se legalizó la nueva agrupación, no fue transparente ni sensata con los residentes. Cosa que pudimos comprobar por manifestaciones de sus habitantes meses después.

Para llevar a cabo la legalización de la nueva agrupación, la Ley dice que deben estar de acuerdo el 70\%

${ }^{7}$ ROCHA, César. Conocimiento y ciudadanía: una construcción posible desde la comunicación para el desarrollo, Policopiado.

${ }^{8}$ REGUILLO, Rossana, Identidades culturales y el Espacio Público: Un 
de los propietarios, no arrendatarios, tener personería jurídica seleccionada por según su criterio para luego formalizarla.

\section{¡Así fue y no lo contaron!}

Pues esto no ocurrió así. La división fue impuesta por sus líderes que realizaron una Asamblea General, donde los invitados eran residentes de las zonas A y B, y según Dávila y algunos residentes de dicha zona (Carlos Marín y Hugo Cepeda, quienes presenciaron la reunión), no hubo quórum, pero en los papeles presentados a la Alcaldía Local se afirmó que la asistencia representó al $80 \%$ de los propietarios.

El tema de las firmas siempre era abordado por nuestros entrevistados con un clima de desconfianza, respondían con palabras entrecortadas y esquivas miradas, les contaremos porqué:

La última Asamblea General de Copropietarios, es decir, de las zonas C y D, para elegir los nuevos delegados, se llevó a cabo el 16 de mayo de 2004, pero en dicha reunión el caos y la tensión a causa de la información sesgada por parte de sus líderes generaron que la opinión pública se convirtiera en "ese fantasma que pretende atrapar las encuestas, es ese o esa ciudadana que habita en la imaginación de los políticos afanados en la captura de voluntades electorales, es esa fuerza que se intuye importante para el impulso de ciertos temas en el espacio público y, sobre todo, es esa optimizada valoración de la memoria y de la capacidad de hacer de las sociedades."

Mapa de los Silencios, pág. 10

${ }^{9}$ RINCÓN, Omar. Cuadernos de Nación: Relatos y memorias leves
Aquel día la sesión se levantó por falta de quórum y los asistentes se molestaron, pues les parecía un irrespeto que no escucharan a los que sí se encontraban presentes y estaban en todo su derecho.

El presidente de la junta, Fernando Dávila, declaró a la jornada como Asamblea Informativa. A esto se le sumó la intervención que ese día realizó el señor Alfredo Erazo del Bloque C8, quien acusó a la Asociación de Copropietarios, es decir, a los representantes de la zona C y D de alterar el número de votantes con firmas de personas muertas o que nunca asistieron. iY se armó la grande!

Erazo le comprobó a la comunidad con acta de defunción en mano, que su vecino fallecido en un trágico accidente aéreo junto con su esposa, se encontraba en la lista de los que apoyaban la división; así como algo más absurdo: él aparecía en la lista de los votantes con su esposa y según acotó el residente, se encontraba fuera de la ciudad.

Como lo explica el más empecinado estudioso de la colombianidad William Ospina (la Revista de El Espectador, 64, oct. 7, 2001): "Esa malicia indígena fue una estrategia de resistencia porque si se predica la igualdad, pero en la práctica se consagran los privilegios y la exclusión, la gente asume que la trampa es legítima, y empieza a su vez a hacer la trampa, porque sabe, y a eso llamamos aquí la malicia indígena, ya que quienes predican la ley no la respetan, todo no es más que un juego diseñado para que pierdan los débiles". A lo cual agrega Omar Rincón: "Malicia indígena para crear, malicia indígena para delinquir; recursividad para resistir al explotador, incentiva para evadir la ley."

de Nación, pág. 35

${ }^{10}$ AROCENA, José. El desarrollo local, un desafío contemporáneo. 


\section{La defensa}

La junta directiva se pronunció ante este hecho aclarando que el caso correspondía a una persona que en el mes de abril de 2003 participó en la Asamblea del Bloque $C 8$, donde se discutía el reglamento de Propiedad Horizontal, y que el señor falleció en el mes de mayo, es por eso que aparece la firma de este señor en los documentos aprobatorios del reglamento.

Allí se acrecentó el conflicto... ¿A qué se debió esa intervención atacando su zona?, Sencillamente es muy buen amigo del señor Segundo Carreño, líder de la Agrupación de Copropietarios, es decir, de la zona A y B y le hizo un favor.

Realizamos campañas apoyando a la Junta de Acción Comunal para preservar la unidad administrativa del conjunto y así evitar que esta división afectara la convivencia en este sector, lo cual no se logro, derivando las siguientes consecuencias:

En materia de aseo y seguridad: La antigua administración tuvo que liquidar a la mitad del personal de mantenimiento, sin contar a los vigilantes.

Arrendatarios: Un hecho que aún continúa ocurriendo y afectando a los propietarios que tienen en arriendo sus apartamentos son los trasteos. Con la vigilancia por zonas, no les garantiza que al momento de desocupar los apartamentos éstos se encuentren a paz y salvo con la administración, lo cual ocasiona cuentas pendientes a los propietarios por pagos administrativos.

Pero, ¿de qué manera se está realizando dicha maniobra? Sencillo, si usted habita por ejemplo, en el bloque $A 7$, se dirigen hacia las porterías de las zonas C y D para sacar su trasteo. Una vez llega allí, los vigilantes nos les pueden exigir el paz y salvo por que como no pertenecen a esta zona, deben permitir su paso.

Parqueaderos: Por otro lado, la adjudicación de parqueaderos también se ha convertido en un dolor de cabeza para los residentes, primero porque la capacidad de cada parqueadero es diferente y por la ubicación de las zonas A y B, que si decidieran encerrar, se quedarían con cuatro de los seis parqueaderos, que de hecho era lo que querían en un principio.

Don Roberto Páez, secretario de la asociación de las zonas $C$ y $D$, guardaba su carro en un parqueadero que le fue asignado a la nueva agrupación. Una mañana salió del conjunto como era usual, pero cuando volvió, le tomó por sorpresa que no le permitieran ingresar su carro por pertenecer a "los de arriba". A esto se le suma que el personal de vigilancia es nuevo y exclusivo para los residentes de esta zona.

En conclusión, los vigilantes sólo acatan órdenes de sus jefes. Finalmente, el carro de Don Roberto fue trasladado a un parqueadero correspondiente a su zona, la C y la D.

Cuartos de basura: Pero aún hay más. Los cuartos de basura son dos, la ubicación de éstos quedan en la mitad de los dos bandos, por nombrarlo de alguna manera. Por lo menos coinciden en el horario para sacar la basura.

El que queda ubicado hacia la calle 83 corresponde a "los de arriba", pero para efectos del mantenimiento y aseo del mismo. El de la calle 86 (parqueadero 2) le corresponde a la otra parte para los mismos efectos.

Estos cuartos se dividen en responsabilidades para el aseo pero todos los residentes, sin excepción, pueden echar la basura en cualquiera de los dos (2) cuartos. 


\section{Ciudadanías}

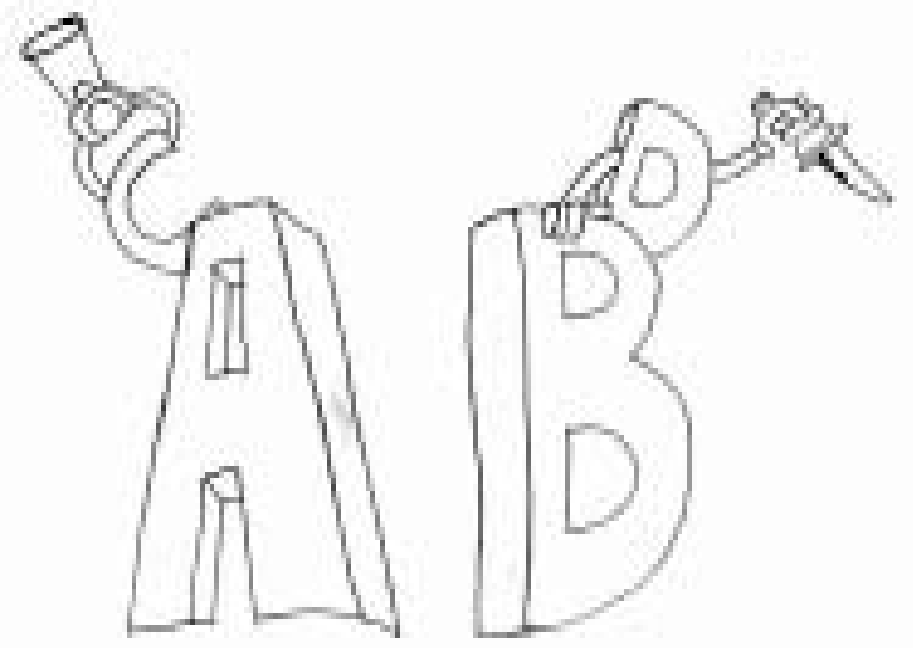

El señor Luis Carlos Rodríguez, residente y vocero del bloque D1, fue insultado por parte de la vigilancia de los del $A$ y del B, al tratar de depositar su bolsa de basura en la designada a la otra agrupación. No es muy difícil adivinar el por qué.

Motobombas y Parabólica: Las dos motobombas que hay, están ubicadas en las zonas $C$ y D. Este también fue un tema de confrontación. Donde se encuentra la motobomba de la zona A y B, está la parabólica que no se encuentra a cargo de dicha zona. El problema se generó cuando el técnico que le hace mantenimiento a la parabólica fue a ingresar al lugar y en la puerta encontró una cadena con un candado que impidió su paso.

Las razones que argumentaron a esta acción se limitaron a que esas eran sus motobombas y nadie de "los de arriba" podía ingresar. Este conflicto se resolvió con la intervención de la Policía.

Parques: Ni las zonas comunes como los parques se salvan. 
Lastimosamente esta situación que desde sus inicios fue de carácter administrativo, se trasladó a otras instancias: desde enfrentamientos personales efectuados por sus mismos delegados, hasta confrontaciones entre los niños, como reflejo de la conducta de los adultos.

También se han presentado manifestaciones de agresión verbal hacia los vigilantes de la zona contraria, aprovechando su libre desplazamiento por el sector.

Etapa final: La etapa final de la división administrativa del Conjunto Residencial Bochica I se llevó a cabo el 30 de enero de 2004 por decisión de la Alcaldía Local de Engativá, que medió en el conflicto y escuchó a las partes.

Hubo una última reunión en la que se dividieron las responsabilidades. El 6 de febrero de 2004, en las instalaciones del Despacho de la alcaldesa, Elizabeth Tuberquía Vanegas, se encontraron los delegados del Departamento Administrativo de Acción Comunal, la Oficina Jurídica de la Alcaldía, la Oficina de Mediación y Conciliación, la representación de la Junta Administrativa Local de Engativá y los delegados de las partes.

\section{Decisiones y preacuerdos}

- $\quad$ Parqueaderos: La Agrupación (A y B) administrará los parqueaderos 2, 3 y 4. La Asociación (C y D) administrará el 1 y el 6. En cuanto al parqueadero \#5, no hubo acuerdo por lo tanto continuará siendo administrado por la Asociación respetando los cupos de las zonas A y B.

- $\quad$ Cuartos de basura: La que se encuentra junto al parqueadero \# 5, será aseado y desinfectado por la Asociación ( $C$ y D). El que se encuentra ubicado junto a la parabólica, será aseado y des- infectado por la Agrupación (A y B). Sin embargo, en cualquiera de los dos cuartos, los residentes de las cuatro agrupaciones pueden depositar la basura.

- $\quad$ Cartera Morosa: La manejará la zona C y D, la otra parte iniciará su administración desde cero.

- $\quad$ Personal de mantenimiento: Se acordó el retiro de las aseadoras y vigilantes que prestaban el servicio en las zonas A y B a partir del primero de febrero de 2004.

- $\quad$ Motobombas: Desde el 7 de febrero se entregará la motobomba que presta servicio a las zonas $\mathrm{A}$ y B con su correspondiente inventario.

- $\quad$ Salón comunal: No se logró acuerdo sobre éste en particular. La justicia ordinaria definirá mediante un fallo. Mientras se resuelve, seguirá siendo administrado por la Asociación (C y D).

- $\quad$ Bienes comunes: Las zonas libres como los parques, las canchas de baloncesto, voleibol y microfútbol pueden ser utilizadas por todos los residentes.

- $\quad$ El sistema de antena parabólica: Lo administrará la Asociación de Copropietarios de las zonas C y D.

\section{El proceso de investigación:}

El proceso de investigación se realizó con la colaboración y apoyo únicamente de la administración de la zona C y D, pues la Agrupación A y B no mostró interés alguno por mejorar las relaciones de convivencia, y debido a su campaña por la división, dilataron el clima de sociabilidad y confianza construido en el sector hace 22 años.

¿Pero cuál es el interés en el no interés?, ¿por qué tanta 
indeferencia? Encontrar una forma de desarrollo que brinde soluciones inmediatas o a largo plazo, no es tarea fácil y mucho menos cuando no existe un reconocimiento monetario por parte de los ejecutores del proyecto social hacia la comunidad.

La comunicación con la Asociación de las zonas C y D siempre estuvo a nuestra disposición. Este grupo realizó visitas por cada uno de los bloques exponiendo la Ley de Propiedad Horizontal, promoviendo la campaña por la unidad y por medio impreso le hicieron frente a las calumnias de carácter administrativo de las que fueron acusados. Hubo un aporte importante por resaltar, esta agrupación fue la que lideró la jornada de elección el 24 de febrero de 2004 donde se convocó a la comunidad Bochica l, para que participara en esta votación abierta y decidiera sobre la división.

Nunca tuvimos respuesta alguna por parte de la Agrupación de Copropietarios de las zonas A y B. Se negaron a nuestras entrevistas, como habitantes y como investigadoras. Hemos hablado con residentes de este sector en particular y aún están en desacuerdo con dicha decisión, y nuestra correspondencia, sigue sin respuesta... Pero haciendo uso de nuestros derechos como ciudadanas colombianas, instauramos un derecho de petición a la cual tampoco hubo respuesta.

"No es posible la existencia de procesos exitosos de desarrollo local sin un componente identitario fuerte, que estimule y vertebre el potencial de iniciativas de un grupo humano"10

Como transformadoras de esa realidad continuamos

Centro Latinoamericano de Economía Humana (CLAEH), Universidad Católica del Uruguay, 1995

${ }^{11}$ Diccionario básico de la lengua española, Bogotá, editorial Norma, demostrando que una comunidad no es solamente un espacio geográfico compartido, sino que allí dentro reside todo un mundo de significaciones y sentidos de vida, que atrapan, transforman y hacen descubrir que el verdadero vivir se simplifica en que no existen fórmulas concretas para la consecución del progreso, es cuestión de sentido común y de entrega.

Este trabajo comunitario se lideró con una visión desde lo colectivo, es decir, pensado en conjunto para nuestra comunidad. Porque no sólo es pensar para ella, es vivir con ella, formar parte y adaptar nuestros conocimientos como profesionales y brindarlos como un elemento transformador de la realidad, obviamente con miras hacia el desarrollo.

Según el diccionario de bolsillo, Edición Norma, "El desarrollo en una de sus acepciones, es el crecimiento económico de un área geográfica o de un Estado, que provoca una mayor calidad de vida en sus habitantes"11, y nos atrevemos a agregarle algo: situación que ocurre sí y solo sí, sus habitantes permiten crear espacios de acción y formación, flexibles a la comprensión, aceptación y escucha de la intervención del otro, del vecino, sin exclusión alguna.

Un desarrollo que se complemente con la heterogeneidad de pensamientos en esa "área geográfica o Estado" puede alcanzar exitosos procesos.

Por ello, sin tener mayor espera se decidió iniciar con un proceso de reconocimiento de los líderes de la comunidad para que incentiven a otros habitantes a participar en los encuentros comunitarios, esto con el fin de hallar en la comunidad una tercera fuerza que impulse y lidere

supropia voz ante sus tepresentantes.
1997.
${ }_{12}$ ROCHA, César. Conocimiento y ciudadanía una construcción




\section{Métale tercera}

Esta tercera fuerza es "El resplandor de mis años" un grupo de adultos mayores liderado por la señora Marta Wilches quien ha destinado gran parte de su vida al trabajo con comunidades, destacando la importancia de tener una vida en mejores condiciones y más digna, eso lo entienden los más de ochenta adultos mayores que conforma el grupo de los barrios: Quirigua, Bachué (barrios aledaños) y Bochica l, desde hace cuatro años.

"La comunicación para el desarrollo se puede vivenciar en cualquier espacio, lo importante es que busque la constitución de ciudadanías creativas"12.

Doña Marta es uno de esos "verdaderos quijotes ubicados en los más apartados rincones del país, quienes con mayor o menor grado de organización o desorganización trabajan

posible desde la construcción para el desarrollo.

13 TÉLLEZ Garzón, María Patricia. La televisión comunitaria en Colombia. $\mathrm{O}$ de cómo la perseverancia trae ventura.

${ }^{14}$ GUERRERO, Amado y JAIMES Óscar. 
día a día por sacar adelante una utopía que se ha convertido para la mayoría en un proyecto de vida, al que le han apostado todo y por el que han tenido satisfacciones y desencantos...".13

"El resplandor de mis años" se hizo partícipe del proceso, allí identificamos que el realizar encuentros comunitarios con personas aledañas al sector y de Bochica I nos permitiría hacer un acercamiento para reflexionar sobre lo colectivo y utilizar herramientas comunicativas en función de la conciencia de lo público ya que la división administrativa quebrantó los lazos de solidaridad y confianza construidos hace más de 21 años entre los residentes.

Tuvimos una bienvenida calurosa por parte de ellos y nos dimos cuenta que "la flaca Martica" como suelen decirle sus abuelos, siempre tiene una sonrisa y una palabra de aliento para cada uno.

Todas las mañanas, vestidos con ese gran resplandor que los caracteriza, se reúnen en el parque central de Bochica I, un grupo de abuelos con tiernas sonrisas y mucha vitalidad para iniciar su rutina de ejercicios, para levantar no sólo sus piernas y brazos sino también su alma altiva.

Están privilegiados de una particularidad que ellos definen como "acoger en su cuerpo un corazón dispuesto a escuchar y a compartir".

Con el grupo encontramos deseos de trabajar de hacer parte de este equipo, por ello, es de suma importancia hacer un llamado a la reflexión sobre el verdadero papel de un buen líder, en donde su principal objetivo sea asumir con responsabilidad los derechos y deberes de su comunidad y que de igual manera, éste motive y multiplique la participación en procesos de desarrollo

\section{Ciudadanías}

y que vincule la voz del otro.

Nos acercamos a ellos el 5 de diciembre de 2003, con el ánimo de hacerlos partícipes de nuestro proyecto. Este encuentro se dio porque la utilización del espacio del parque, que es un bien común, le fue reclamada a su directora por parte de algunos residentes que agredieron verbalmente a ella y a su grupo.

El conflicto de la división también los tocó. "Los residentes que manifestaron estar molestos por la utilización del parque, fueron invitados a que se vincularan al grupo en las actividades deportivas y sociales que practican. Esto con el fin de hacerlos partícipes en la "utilización de su espacio" como ellos mismos decían", afirmó Marta mientras nos muestra una carpeta con la programación del semestre.

Este grupo no sólo se reúne para hacer ejercicio, también practican asistencia social; visitan a los enfermos, llevan mercado y ropa a hogares que viven una difícil situación económica, se presentan en el parque, en los teatros, en donde los inviten con el grupo de danzas y ahora participan con nosotras en un proceso de capacitación por medio de los encuentros comunitarios apoyándonos desde la ciencia de la comunicación, para generar aportes que contribuyan con la convivencia en el Conjunto Residencial Bochica I.

En nuestro proceso de investigación los espacios que hemos concebido para el diálogo y la interacción hacia la comunidad, no sólo han generado reconocimiento e identidad entre los mismos residentes, sino que reconstruye tejido social aportando políticas de convivencia en el sector.

Participación y desarrollo local, prioridad regional de las universidades. Bogotá. 
"Generalmente, al ciudadano se lo define siempre jurídicamente, en donde sólo tiene derechos y obligaciones. Esa es una visión, real pero sumamente parcial. Lo que hay que pensar es que es un ciudadano que pertenece a una sociedad y tiene derecho de participar en ella a pesar de que pueda no querer hacerlo"14

De esta manera, los encuentros comunitarios se consolidan en una herramienta que facilita y activa la participación, integración, aceptación y vinculación a procesos de desarrollo social, donde no existe un límite de edad, género o profesión para alcanzar una mejor calidad de vida.

Un encuentro comunitario es un encuentro con mi otro yo, que es mi vecino, mi amigo, mi colega y mi hermano, que comparte los mismos sueños olvidados por una Nación, pero que no se relega a aceptar imposibles. Hablar o callar, iusted decide!

\section{Junio de 2005, la lucha continúa}

Lo que parecía inalcanzable se logró, después de tres años de trabajo con la comunidad, se conformó un grupo estable de residentes, quienes buscamos unificar nuestra comunidad con el Comité Pro Unidad Bochica l, comenzamos ocho y vamos 60.

La lucha continúa y la investigación desarrollada aquí se convirtió en un proyecto de vida no solo para nosotras, también para las más de 2000 personas que allí residimos.

Acosta de viejotecas, bingos y ventas de arroz con leche, masato y empanada en el parque, hemos logrado mantener un presupuesto para papelería, caja menor para los ["Jmités existentes (logística, jurídico, divulgación y organización) cubrir los costos de los foros que se realizan en el salón comunal y que se transmiten en directo por la parabólica, llegando a todos los hogares del conjunto.

Estos foros han sido liderados por un abogado experto en Propiedad Horizontal, residente de la Zona A que aporta su trabajo y experiencia para la creación del Reglamento de Bochica I sin cobrar dinero alguno.

Estamos a un mes para las votaciones en la Asamblea General, debemos obtener el 70\% de las firmas de los habitantes, no arrendatarios que apoyen la unidad y de esta manera cumplir el gran sueño de tener una sola administración y una comunidad. Por que Bochica I solo hay uno.

\section{Bibliografía}

AlFARO, Rosa María. Comunicación y ciudadanía para una sociedad en movimiento. Extracto de su ponencia en el seminario del año 2000. Asociación de Comunicadores Sociales CALANDRIA y Universidad de Lima, Perú.

AROCENA, José. El desarrollo local, un desafío contemporáneo. Centro Latinoamericano de Economía Humana (CLAEH), Universidad Católica del Uruguay. 1995

GUERRERO, Amado y JAIMES Óscar. Participación y desarrollo local, prioridad regional de las universidades. Bogotá. 